\title{
(C) OPEN ACCESS \\ Characteristics of the case mix, organisation and delivery in cancer palliative care: a challenge for good-quality research
}

\author{
M J Hjermstad, ${ }^{1,2} \mathrm{~N}$ Aass, ${ }^{1,3} \mathrm{~F}$ Aielli, ${ }^{4} \mathrm{M}$ Bennett, ${ }^{5} \mathrm{C}$ Brunelli, ${ }^{2,6}$ \\ A Caraceni, ${ }^{2,6}$ L Cavanna, ${ }^{7} \mathrm{~K}^{2}$ Fassbender, ${ }^{8} \mathrm{M}$ Feio, ${ }^{9} \mathrm{D}$ F Haugen, ${ }^{2,10,11}$ \\ G Jakobsen, ${ }^{2}$ B Laird ${ }^{2,12}$ E T Løhre, ${ }^{13} \mathrm{M} \mathrm{Martinez,}^{14} \mathrm{M} \mathrm{Nabal,}^{15}$ \\ A Noguera-Tejedor, ${ }^{16} \mathrm{~K}$ Pardon, $^{17,18} \mathrm{~A} \mathrm{Pigni}^{6}{ }^{6} \mathrm{~L} \mathrm{Piva}^{19}$ \\ J Porta-Sales, ${ }^{20,21,22} \mathrm{~F} \mathrm{Rizzi}^{23} \mathrm{E}$ Rondini, ${ }^{24} \mathrm{P}$ Sjøgren, ${ }^{25} \mathrm{~F}$ Strasser, ${ }^{26}$ \\ A Turriziani, ${ }^{27} \mathrm{~S}$ Kaasa, ${ }^{2,13}$ on behalf of the European Palliative Care \\ Cancer Symptom study (EPCCS)
}

For numbered affiliations see end of article.

\section{Correspondence to} Dr M J Hjermstad, Department of Oncology, Regional Centre for Excellence in Palliative Care, Oslo University Hospital, Ullevål, Box 4956, Nydalen, Oslo 0424, Norway;

marianne.j.hjermstad@ntnu.no

Received 7 August 2015 Revised 5 February 2016 Accepted 10 May 2016 Published Online First 31 May 2016

\section{Check for updates}

To cite: Hjermstad MJ, Aass N, Aielli F, et al. BMJ Supportive \& Palliative Care 2018;8:456-467.

\section{ABSTRACT}

Objectives Palliative care (PC) services and patients differ across countries. Data on PC delivery paired with medical and self-reported data are seldom reported. Aims were to describe (1) PC organisation and services in participating centres and (2) characteristics of patients in PC programmes.

Methods This was an international prospective multicentre study with a single web-based survey on PC organisation, services and academics and patients' self-reported symptoms collected at baseline and monthly thereafter, with concurrent registrations of medical data by healthcare providers. Participants were patients $\geq 18$ enrolled in a PC programme.

Results 30 centres in 12 countries participated; 24 hospitals, 4 hospices, 1 nursing home, 1 home-care service. 22 centres (73\%) had PC in-house teams and inpatient and outpatient services. 20 centres (67\%) had integral chemotherapy/radiotherapy services, and most (28/30) had access to general medical or oncology inpatient units. Physicians or nurses were present 24 hours/7 days in 50\% and $60 \%$ of centres, respectively. 50 centres $(50 \%)$ had professorships, and 12 centres (40\%) had fulltime/part-time research staff. Data were available on 1698 patients: 50\% females; median age 66 (range 21-97); median Karnofsky score 70 (10100); 1409 patients (83\%) had metastatic/ disseminated disease; tiredness and pain in the past 24 hours were most prominent. During follow-up, 1060 patients (62\%) died; 450 (44\%) $<3$ months from inclusion and 701 (68\%) within 6 months. ANOVA and $\chi^{2}$ tests showed that hospice/nursing home patients were significantly older, had poorer performance status and had shorter survival compared with hospital-patients $(p<.0 .001)$.

Conclusions There is a wide variation in PC services and patients across Europe. Detailed characterisation is the first step in improving PC services and research.

Trial registration number ClinicalTrials.gov Identifier: NCT01362816.

\section{INTRODUCTION}

The WHO definition of palliative care (PC) states that it should be available early in the disease trajectory and may be delivered alongside potentially curative treatments. ${ }^{1}$ However, only 1 in 10 of those who need PC receive it. ${ }^{2}$

One reason for this may be that PC has often been misconstrued as end-of-life care $^{3}$ and consequently referrals occur too late. A retrospective study showed that referrals took up to 16 months after being diagnosed with advanced cancer, with a median interval between the PC consultation and death of 1.4 months. ${ }^{4}$ However, there is now a persuasive argument that introducing PC early in patients with advanced disease has beneficial effects on physical symptoms, psychological distress, prognostication and survival. ${ }^{5-7}$

Despite the positive development of palliative care units (PCUs) and PC specialist training for doctors and nurses, ${ }^{8}$ the integration of PC and oncology 
services varies widely. Furthermore, establishing PC as an academic field in its own right has progressed slowly. ${ }^{9} \quad$ Recently, two large-scale European Commission funded projects, IMPACT (http://www. impactpalliativecare.eu/) and EURO IMPACT (http:// www.euro-impact.eu/), have developed a set of recommendations for policymakers and decision-makers to help improve the quality of and access to PC in an ageing Europe ${ }^{10}$ focusing on improving the quality of care at all levels and that specialist PC services should be available in all healthcare settings.

The first step in meeting these recommendations is to characterise PC services and their patients across multiple centres, settings and countries in Europe. To this end, the European Palliative Care Cancer Symptom study (EPCCS) was developed, supported by the European Association for Palliative Care (EAPC) Research Network (http://www eapcrn.org/) and the European Palliative Care Research Centre (http://www.ntnu.edu/prc/).

We present here the main report from the EPCCS study, which describes the organisation and delivery of PC at specific centres across Europe. The key clinical characteristics of the patients at these centres are also described.

\section{MATERIALS AND METHODS}

Invitations to participate were distributed to EAPC-RN and PRC members and advertised at EAPC conferences.

The data collection consisted of three parts:

A. Assessment of PC service: a single web survey on organisational and economic issues

B. Registration of patients' medical data using a case report form completed by the healthcare providers (HCP-CRF) at each patient encounter

C. Patients' self-reported data (patient-CRF) completed at each patient encounter.

All forms were forward-backward translated into the language of the participating centre.

\section{Assessment of PC service}

A one-time registration of institutional data was done using an English language web-based survey. This was completed in 2010 before any patients were included. The survey consisted of four parts covering (1) institution details; for example, type of hospital, size and catchment area, (2) description of the PC programme; for example, size, composition, types of PC services and anti-cancer treatment, (3) organisational issues and academic affiliations and (4) funding sources.

\section{The healthcare provider-CRF}

The HCP-CRF consisted of a brief set of medical and treatment-related variables, informed by the EAPC basic data set that was under development at the time, ${ }^{11}$ a four-item version of the mini-mental state examination (MMSE) ${ }^{12}$ using the suggested cut-off of four (of maximum eight) to indicate possible cognitive failure, ${ }^{13}$ and the Karnofsky Performance Status Scale. ${ }^{14}$ A retrospective recording of date of death was performed in February 2014, 6 months after inclusion of the last patients.

\section{The patient CRF}

The patient CRF consisted of key sociodemographic items: age, sex, education and living situation and questions about common cancer-related symptoms. This included two items from the Brief Pain Inventory $(\mathrm{BPI})^{15}$ average and worst pain intensity during the past 24 hours, to be answered on a $0-10$ numerical rating scale, two dichotomous questions on neuropathic pain (NP) symptoms (skin sensitivity/numbness) and breakthrough pain (BTP) adapted from Pain Detect $^{16}$ and the Alberta Breakthrough Pain Assessment Tool, ${ }^{17}$ respectively. Depression was assessed by the two items on anhedonia and depressed mood from the Brief Patient Health QuestionnairePHQ9 ${ }^{18}$ corresponding to the main items in the DSM-5 criteria for depression and assessing the frequency at which they have been bothersome during the past 2 weeks: $0=$ 'not at all', $1=$ 'several days', $2=$ 'more than half the days' and $3=$ 'nearly every day'. Furthermore, the revised version of the Edmonton Symptom Assessment System (ESAS-r) ${ }^{19}$ and the PC version of the European Organisation for Research and Treatment of Cancer Quality of Life Questionnaire (EORTC QLQ-C15-PAL) ${ }^{20}$ were used. The physical function scale of the QLQ-C15-PAL was scored from 1: 'not at all' to 4 'very much' transformed to a $0-100$ scale.

\section{PATIENTS AND SAMPLING}

Eligible patients were: enrolled in the centre's PC programme: advanced, incurable cancer; age $\geq 18$ years; written informed consent; eligible for at least one follow-up assessment after inclusion. Exclusion criteria were: patients being treated with curative intent; inability to comply with the study due to psychotic disorders, severe cognitive impairment or language problems; imminent death; or inability to come for follow-up due to medical, social or geographical reasons.

\section{Ethical considerations}

The study was performed according to the Declaration of Helsinki and was registered in the ClinicalTrials.gov database (No. NCT01362816). Ethical approval was obtained at each site.

\section{Statistical analyses}

Standard descriptive statistics, $\chi^{2}$ tests and one-way ANOVAs were used to compare subgroups for the web survey and patient data as appropriate. Data from ESAS-r are presented as mean scores (SD) and categorised severity: $0-3=$ none/mild, $4-6=$ moderate and 
$7-10=$ severe. The significance level was set at $p<0.05$. The ANOVA analyses were corrected for multiple comparisons using Bonferroni adjustments, with a resulting $\mathrm{p}<0.00625$. Dunnett's T3 or Tukey's post hoc tests were performed to test for differences in patient characteristics between centre categories. The ANOVAs were performed with the predefined four centre categories: cancer centres with PC beds, without PC beds, regional hospitals and hospices/ nursing homes and also repeated using the following three categories: centres with PC beds, without PC beds and hospices/nursing homes. Survival was categorised in days <30, 30-89, 90-149, 150-179 with the latter category representing 6 months survival or longer. Sample size calculations were not performed as this was not a hypothesis-testing study. IBM SPSS Statistics V.20.0 for Windows (IBM Corporation, Armonk, New York, USA) were used for data analysis.

\section{RESULTS}

\section{The web survey}

Thirty-seven centres completed the web survey; the 30 centres that included patients presented were across 12 countries: Australia, Belgium, Canada, Denmark, Georgia, Germany, Italy, Norway, Portugal, Spain, Switzerland and the UK. The study ran from April 2011 through October 2013.

Table 1 shows characteristics of the participating centres, 27 European, 1 Australian, 2 Canadian. The majority, 24/30 (80\%), were hospitals, in addition to four hospices, one nursing home and one PC home care service. Most centres (18/30, 60\%) had rural and urban catchment areas; the remaining $40 \%$ covered urban areas.

Sixteen (67\%) of the participating hospitals had designated inpatient PC beds, 28 (98\%) had PC outpatient units and $25(83 \%)$ had PC teams. A patient hotline for contact and questions was available in 19 (63\%) centres. The annual number of PC patients treated ranged from 113 to 729 , and 13 (43\%) centres reported that patients with cancer constituted $90 \%$ or more of their PC patients.

State and/or community funding was predominant (26/30). Almost all centres (28/30) had easy access to general medicine or oncology inpatient units (26/30), as well as diagnostic facilities such as basic radiology (27/30), MRI (24/30), CT (24/30) and PET (16/30) scans. Twenty centres had chemotherapy and radiotherapy as part of their PC programmes, while one provided radiotherapy only. This was supplemented with other anti-cancer therapies such as targeted therapy, hormonal treatment and immunotherapy in 12 centres, while 9 centres did not provide any anti-cancer therapy. The average length of stay reported by the centres with inpatient PC beds varied from 7 to 73 days.

In all but three centres, the PC programme was led by a physician, two heads had a nursing background, while one centre had a joint physician/nurse leadership. In 8 of the 30 centres, the lead practitioner had specialist PC training (seven physicians, one nurse). As per table 1 , the number of physicians with specialist training and presence of physicians and nurses varied within the programmes. Physicians were physically available $24 / 7$ in 17 of the 30 centres and on phone in $23 / 30$ centres, while the corresponding numbers for nurses were 19/30 and 16/30 centres, respectively. Several other professions were also part of all PC programmes, most often social workers $(n=15)$, psychologists and physiotherapists ( $\mathrm{n}=12$, both).

Professorships were present in 15 of the 30 PC programmes, varying from 0.2 to 3 full-time equivalents (table 1); 13 had a medical background. Academic positions, defined as research staff not doing clinical work, were present in 15 centres, varying from 0.3 to 8 full-time equivalents (senior researchers, $\mathrm{PhD} /$ master students). Two of the six centres in the hospicenursing home category had part-time professorships.

\section{Patient characteristics}

Of the 1739 patient records, 41 were not included in the analyses, as the HCP $(n=31)$ or patient CRFs $(n=9)$ or both $(n=1)$ were not completed at inclusion. Records with occasional missing values for single variables were retained, leaving a study sample of 1698 patients. Most patients, 46\% ( $\mathrm{n}=778)$, were included at hospital PC services, followed by general oncology departments (35\%). Sixty-one per cent $(n=1017)$ were outpatients.

The median age was 66 (range 21-97), and 50.2\% were females (table 2). The mean MMSE score on the 0-5 scale was 4.5 (SD 0.9), with $29 \%$ having a score below 4 , suggesting a degree of cognitive failure. ${ }^{18}$ The predominant diagnoses were gastrointestinal (31\%), lung $(20 \%)$ and breast cancer $(17 \%)$. One or more comorbid conditions were reported in 60\%, with heart disease being most common (28\%; table 2). Eighty-three per cent had disseminated or metastatic disease, with bone (37\%), liver (30\%) and lung (30\%) metastases being most frequent.

Anti-cancer therapy was received by 1015 patients $(60 \%)$ at inclusion: chemotherapy $(\mathrm{n}=707 / 42 \%)$ and hormonal therapy $(\mathrm{n}=172 / 10 \%$; table 2$)$. Twenty-seven per cent of patients who died between 1 and 3 months after inclusion and $15 \%$ of those who died within 30 days from inclusion received chemotherapy at study entry. Fifty-nine per cent $(n=991)$ were using opioids at baseline: this was sole analgesic therapy in $20 \%$ (198), combined with other analgesics in 793 (80\%). Anti-depressants to treat depression were used by $16 \%$.

A total of 1060 patients (62\%) died during follow-up. Survival length for the 1035 patients with a verified date of death is categorised in table 2 and shows that $68 \%$ of these died within 6 months from inclusion. 


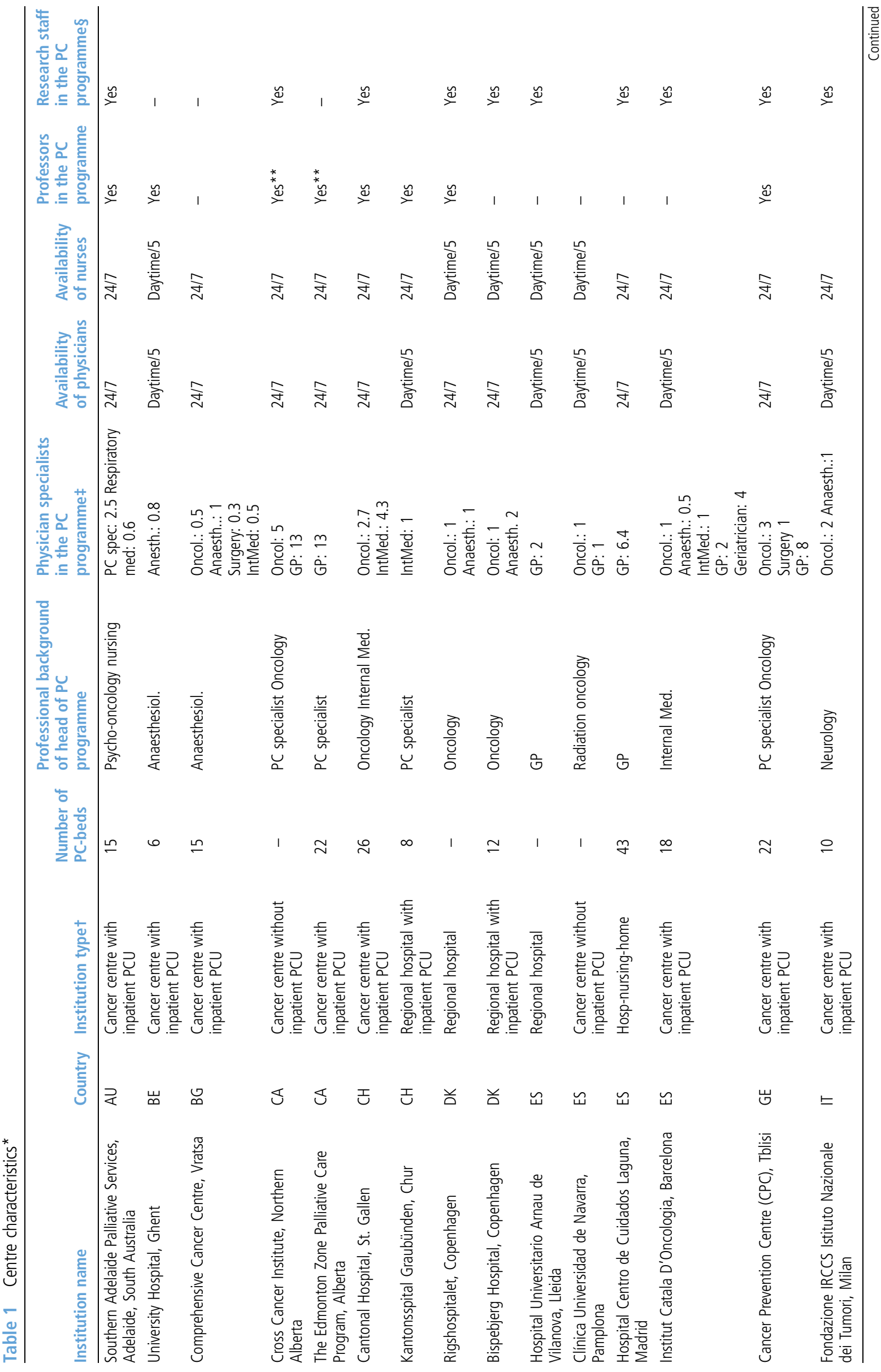


Table 2 Patient characteristics at inclusion

\begin{tabular}{|c|c|c|}
\hline Variable & $\begin{array}{l}\mathrm{N}=1698 \\
\mathrm{n}(\%)\end{array}$ & Missing, $\mathrm{n}$ \\
\hline Gender & & 0 \\
\hline Female & $852(50.2)$ & \\
\hline Male & $846(49.8)$ & \\
\hline Education (years) & & 20 \\
\hline$<10$ & $544(32)$ & \\
\hline $10-12$ & $700(42)$ & \\
\hline$>12$ & $434(26)$ & \\
\hline Living situation & & 7 \\
\hline Alone & $349(21)$ & \\
\hline With spouse/partner & $737(43)$ & \\
\hline With spouse/partner and children & $376(22)$ & \\
\hline With others (children or adults) & $210(13)$ & \\
\hline In an institution & $19(1)$ & \\
\hline Country & & 0 \\
\hline Australia, 1 site & $35(2)$ & \\
\hline Belgium, 1 site & $95(6)$ & \\
\hline Bulgaria, 1 site & $28(2)$ & \\
\hline Canada, 2 sites & $94(6)$ & \\
\hline Denmark, 2 sites & $100(6)$ & \\
\hline Georgia, 1 site & $19(1)$ & \\
\hline Italy, 7 sites & $605(35)$ & \\
\hline Norway, 4 sites & $235(14)$ & \\
\hline Portugal, 1 site & $58(3)$ & \\
\hline Spain, 4 sites & $233(14)$ & \\
\hline Switzerland, 2 sites & $68(4)$ & \\
\hline UK, 4 sites & $128(7)$ & \\
\hline Treatment setting & & 38 \\
\hline Inpatients & $348(21)$ & \\
\hline Outpatients & $1017(61)$ & \\
\hline Home care & $295(18)$ & \\
\hline Comorbidity (numbers) & & 5 \\
\hline 0 & $679(40)$ & \\
\hline 1 & $638(39)$ & \\
\hline 2 & $283(16)$ & \\
\hline 3 or more & $93(5)$ & \\
\hline Primary cancer diagnosis* & & 4 \\
\hline Digestive organs & $520(31)$ & \\
\hline Respiratory organst & $343(20)$ & \\
\hline Breast cancer & $284(17)$ & \\
\hline Male genital organs & $126(7)$ & \\
\hline Gynaecological & $99(6)$ & \\
\hline Urinary & $75(4)$ & \\
\hline Head & $58(4)$ & \\
\hline Leukaemia or lymphoma & $44(3)$ & \\
\hline Malignant connective/soft-tissue tumours & $40(2)$ & \\
\hline Skin cancer/malignant melanoma & $36(2)$ & \\
\hline CNS tumours & $24(1)$ & \\
\hline Secondary/ill-defined malignant tumours & $24(1)$ & \\
\hline Malignant endocrine tumours & $11(1)$ & \\
\hline Other $\ddagger$ & $10(1)$ & \\
\hline
\end{tabular}

Table 2 Continued

\begin{tabular}{|c|c|c|}
\hline Variable & $\begin{array}{l}\mathrm{N}=1698 \\
\mathrm{n}(\%)\end{array}$ & Missing, $\mathrm{n}$ \\
\hline Disease status & & 8 \\
\hline Metastatic/disseminated & $1414(83)$ & \\
\hline Local/locally advanced & $276(17)$ & \\
\hline Survival, days from inclusion & & $663 \S$ \\
\hline$<30$ & $151(15)$ & \\
\hline $30-89$ & $299(29)$ & \\
\hline $90-149$ & $184(18)$ & \\
\hline $150-180$ & $67(6)$ & \\
\hline$>180$ & $334(32)$ & \\
\hline Treatment with chemotherapy at inclusion & & 3 \\
\hline Yes & $707(42)$ & \\
\hline No & $998(58)$ & \\
\hline \multicolumn{3}{|l|}{$\begin{array}{l}\text { Treatment with chemotherapy by the survival } \\
\text { group (days) }\end{array}$} \\
\hline$<30$ & $23(15)$ & \\
\hline $30-89$ & $80(27)$ & \\
\hline $90-149$ & $85(46)$ & \\
\hline $150-180$ & $26(39)$ & \\
\hline$>180$ & $162(49)$ & \\
\hline Treatment with opioids at inclusion & & 22 \\
\hline Yes & $991(59)$ & \\
\hline No & $685(41)$ & \\
\hline
\end{tabular}

*Based on ICD-10 diagnoses from patient records.

tIncluding eight patients with laryngeal cancer.

fIncluding malignant bone tumours $(n=8)$, multiple primary cancers $(n=2)$. $\S$ Incl. 25 patients reported dead, but with no date registered.

Table 3 displays the patients' mean scores on physical functioning, pain and ESAS. Mean scores above 3.0 were found with tiredness (4.3 SD 3.0), drowsiness (3.1 SD 2.9) and well-being (3.6 SD 2.7), and for average and worst pain intensity past 24 hours $(3.2$ SD 2.7 and 4.0 SD 3.3). ESAS scores $\geq 7$, indicating severe symptom intensity, varied from $4 \%$ in nausea to $27 \%$ with tiredness, relative to $15 \%$ and $27 \%$ for average and worst pain intensity, respectively. Thirty-seven per cent confirmed episodes of BTP during the past 24 hours (table 3 ).

Table 4 displays selected medical and patientreported variables grouped by four centre categories: cancer centres with $(n=11)$ and without inpatient PCUs $(n=4)$, regional hospitals $(n=9)$ and hospices/ nursing homes $(n=6)$.

Overall, patients included from the hospice/nursing home category were significantly older, less likely to receive chemotherapy, had poorer physical performance and reported significantly more tiredness compared with patients in the other three centre categories ( $p$ values 0.03 to $<0.001$ ). Their survival time from inclusion was also significantly shorter $(\mathrm{p}<0.001$; table 4$)$. Five of the regional hospitals had PCUs with inpatient beds, and one could argue that it may be arbitrary to differentiate between cancer 
Table 3 Patient self-report of symptoms and physical functioning

\begin{tabular}{|c|c|c|c|c|c|c|c|c|c|}
\hline \multirow[b]{2}{*}{ Variables } & \multicolumn{9}{|c|}{$\mathrm{N}=1698$} \\
\hline & Mean & SD & Missing & $\begin{array}{l}\mathrm{N} \\
0-3\end{array}$ & $\begin{array}{l}\% \\
0-3\end{array}$ & $\begin{array}{l}N \\
4-6\end{array}$ & $\begin{array}{l}\% \\
4-6\end{array}$ & $\begin{array}{l}N \\
7-10\end{array}$ & $\begin{array}{l}\% \\
7-10\end{array}$ \\
\hline$\overline{\text { Pain* }}$ & 2.1 & 2.3 & 14 & 1246 & (74) & 308 & (18) & 141 & (8) \\
\hline Tiredness* & 4.3 & 3.0 & 13 & 654 & (41) & 541 & (32) & 450 & $(27)$ \\
\hline Nausea* & 1.0 & 2.1 & 21 & 1471 & (88) & 138 & (8) & 68 & (4) \\
\hline Depression* & 2.5 & 2.9 & 17 & 1144 & (68) & 318 & (19) & 219 & (13) \\
\hline Anxiety* & 2.3 & 2.8 & 18 & 1183 & (70) & 315 & (19) & 192 & (11) \\
\hline Drowsiness* & 3.1 & 2.9 & 31 & 994 & (60) & 396 & (23) & 277 & (16) \\
\hline Appetite* & 3.0 & 3.2 & 23 & 1322 & (78) & 240 & (14) & 128 & (8) \\
\hline Well-being* & 3.6 & 2.7 & 35 & 837 & (50) & 552 & (33) & 274 & (17) \\
\hline Shortness of breath* & 1.8 & 2.5 & 14 & 1320 & (78) & 238 & (14) & 26 & (8) \\
\hline Pain intensity, average past 24 hours $\dagger$ & 3.2 & 2.7 & 9 & 991 & (59) & 449 & (26) & 249 & $(15)$ \\
\hline Pain intensity, worst, past 24 hours $\dagger$ & 4.0 & 3.3 & 21 & 796 & $(47)$ & 418 & (25) & 463 & $(27)$ \\
\hline \multirow[t]{2}{*}{ Physical functioning $\ddagger$} & 64.3 & 29.2 & 14 & & & & & & \\
\hline & $\begin{array}{l}\mathrm{N} \\
\text { yes }\end{array}$ & $\begin{array}{l}\% \\
\text { yes }\end{array}$ & & & & & & & \\
\hline PHQ9 depression§ & 339 & (20) & 28 & & & & & & \\
\hline Anhedonia & 553 & (32) & 33 & & & & & & \\
\hline Depressed mood & 437 & (26) & 30 & & & & & & \\
\hline Neuropathic pain & 560 & (34) & 65 & & & & & & \\
\hline Breakthrough pain last 24 hours** & 608 & (37) & 44 & & & & & & \\
\hline
\end{tabular}

${ }^{\star}$ ESAS-r: 0-10 scale, higher score implies higher symptom intensity/poorer well-being, 'right now'. ${ }^{19}$

†BPI: $0-10$ scale, higher score implies higher pain intensity. ${ }^{15}$

¥QLQ-C15-PAL: 0-100 scale, higher score implies better functioning. ${ }^{20}$

§PHQ9: 'yes' indicates a score of 2 or 3 on the $0-3$ scale assessing the frequency at which people have been bothered by anhedonia (little interest or pleasure in doing things) and depressed mood during the past 2 weeks: $2=$ 'more than half the days' and $3=$ 'nearly every day'. ${ }^{18}$

$\eta^{\prime}$ Does the skin in the painful area feel different from normal, more numb or more sensitive?': yes/no, adapted from PainDetect. ${ }^{16}$

${ }^{* *^{\prime}}$ Have you had flare-ups of breakthrough pain in the last 24 hours?': yes/no, adapted from the Alberta Breakthrough Pain Assessment Tool. ${ }^{17}$

centres and regional hospitals with inpatient PCUs. Thus, the analyses were repeated with three centre categories: hospitals with $(\mathrm{n}=16)$ and without PC beds $(n=8)$ and hospices/nursing homes $(n=6)$, yielding similar results (data not tabulated).

\section{DISCUSSION}

This is the first study to characterise PC services and patients across a wide range of centres and countries. There were differences and similarities in organisational issues, number of physician specialists, academic affiliations and research activities across the participating centres. Most centres had outpatient clinics, easy access to general medicine or oncology units, and $83 \%$ had in-house PC teams. Cancer was the predominant disease within the PC programmes, and one-third offered chemotherapy and radiotherapy as part of their programme. All centres reported that their PC teams were multidisciplinary, although the size and composition varied.

Overall, patient characteristics based on the HCP registrations correspond to findings from other studies in PC or advanced cancer regarding the most common diagnoses, about $60 \%$ receiving opioids, ${ }^{21-23}$ and a median age around 66 years, ${ }^{5} 24$ albeit higher than some studies. ${ }^{25}{ }^{26}$ Mean scores on the self-reported symptoms on the ESAS resembled previous reports, with tiredness being most pronounced..$^{19} 2124$ It is noteworthy, however, that the mean pain score on the ESAS was $<3$, with only $8 \%$ scoring in the upper range $(\geq 7)$, whereas the mean scores on the average and worst pain items of the BPI exceeded 3, with $15 \%$ and $27 \%$ of patients reporting high pain intensity $(\geq 7)$. This may indicate suboptimal pain treatment, still a persistent problem. ${ }^{27}$ It does once again underline the necessity to use different time windows when assessing pain intensity. A prevalence of BTP of $37 \%$ is lower than the $50 \%$ reported in a review presenting pooled analyses of the BTP literature. ${ }^{28}$ Without a more thorough assessment, it is difficult to ascertain if this reflects true BTP or end-of-dose failure of medication.

Patient characteristics differed when compared across our four predefined categories of participating centres (table 4), and the same differences remained significant when using a three-centre categorisation. The 233 patients within the hospice/nursing home services had a significantly shorter survival, reported significantly more tiredness, were more often receiving opioids and were less prone to get chemotherapy, compared to hospital patients. The fact that $42 \%$ of patients overall were receiving anti-cancer treatment on inclusion may in part be explained by the fact that 
Table 4 Patient characteristics, grouped by centre types*

\begin{tabular}{|c|c|c|c|c|c|}
\hline & $\begin{array}{l}\text { Cancer centre } \\
\text { with PCUt } \\
\mathrm{N}=11\end{array}$ & $\begin{array}{l}\text { Cancer centre } \\
\text { without PCUt } \\
\mathrm{N}=4\end{array}$ & $\begin{array}{l}\text { Regional hospital } \\
\mathrm{N}=9\end{array}$ & $\begin{array}{l}\text { Hospice, } \\
\text { nursing-home } \\
\mathrm{N}=6\end{array}$ & \\
\hline & $\mathrm{N}(\%)$ & N (\%) & N (\%) & N (\%) & p Value \\
\hline No. of patients & $666-685(97-100)$ & $234-230(98-100)$ & $546-534(98-100)$ & $233-224(96-100)$ & \\
\hline Chemotherapy at inclusion & $272(39.8)$ & $119(50.9)$ & $290(53.1)$ & $26(11.3)$ & $<0.001 \S$ \\
\hline Using opioids & $392(58.2)$ & $136(58.4)$ & $311(57.3)$ & $152(67.3)$ & $0.06 \S$ \\
\hline Breakthrough pain & $252(37.8)$ & $77(33.5)$ & $207(38.8)$ & $72(32.0)$ & $0.22 \S$ \\
\hline PHQ9, depression** & $136(20)$ & $45(20)$ & $104(19)$ & $54(24)$ & $0.53 \S$ \\
\hline Survival (days) & $\begin{array}{l}\text { Missing } 237 \\
\mathrm{n}=448\end{array}$ & $\begin{array}{l}\text { Missing } 119 \\
\mathrm{n}=115\end{array}$ & Missing $278 n=268$ & Missing $29 n=204$ & $<0.001 \S$ \\
\hline$<30$ & $58(12.9)$ & $8(7.0)$ & $36(13.4)$ & $49(24.0)$ & \\
\hline $30-89$ & $132(29.5)$ & $27(23.5)$ & $63(23.5)$ & $77(37.7)$ & \\
\hline 90-149 & $86(19.2)$ & $22(19.1)$ & $48(17.9)$ & $28(13.7)$ & \\
\hline $150-180$ & $31(6.9)$ & $13(11.3)$ & $15(5.6)$ & $8(3.9)$ & \\
\hline \multirow[t]{2}{*}{$>180$} & $141(31.5)$ & $45(39.1)$ & $106(39.6)$ & $42(20.6)$ & \\
\hline & Mean (SD) & Mean (SD) & Mean (SD) & Mean (SD) & p Valuett \\
\hline Age (years) & $63.7(12.2)$ & $64.8(11.9)$ & $65.6(12.0)$ & $73.1(11.5)$ & $<0.001$ \\
\hline Karnofsky score & $68.7(15.5)$ & $71.6(13.2)$ & $68.4(17.0)$ & $55.4(15.1)$ & 0.03 \\
\hline Average pain intensity $\ddagger \ddagger$ & $3.1(2.6)$ & $3.2(2.7)$ & $3.2(2.9)$ & $3.2(2.7)$ & 0.95 \\
\hline Worst pain intensitył & $3.9(3.2)$ & $4.3(3.5)$ & $3.7(3.2)$ & $4.0(3.2)$ & 0.84 \\
\hline Tiredness $\S \S$ & $4.0(2.8)$ & $4.5(2.9)$ & $4.5(3.1)$ & $5.0(3.0)$ & $<0.001$ \\
\hline Drowsiness $\S \S$ & $3.3(2.8)$ & $2.8(3.1)$ & $2.8(2.9)$ & $3.3(3.0)$ & 0.01 \\
\hline Well-being§§ & $3.8(2.5)$ & $3.8(2.8)$ & $3.5(2.8)$ & $3.7(2.8)$ & 0.32 \\
\hline Physical functioning & $66.7(28.2)$ & $72.1(25.4)$ & $67.8(27.1)$ & $44.3(31.6)$ & $<0.001$ \\
\hline
\end{tabular}

${ }^{*}$ Grouped according to information given on the web survey.

†PCU: palliative care unit with inpatient beds.

łIncluding one hospice at home-service.

$\S \chi^{2}$ tests for categorical variables.

ף'Have you had flare-ups of breakthrough pain in the last 24 hours?'=yes, adapted from the ABPAT. ${ }^{17}$

**Presence of PHQ9 depression=yes, indicates a score of 2 or 3 on the $0-3$ scale assessing the frequency at which people have been bothered by anhedonia (little interest or pleasure in doing things) and depressed mood during the past 2 weeks: $2=$ 'more than half the days' and $3=$ 'nearly every day'. $^{18}$

†+One-way ANOVAs after correcting for multiple comparisons using Bonferroni adjustments.

$\ddagger \ddagger B P I 0-10$ scale, higher score implies higher pain intensity. ${ }^{15}$

$\S \S E S A S-r$ : 0-10 scale, higher score implies higher symptom intensity/poorer well-being. ${ }^{19}$

ๆๆQLQ-C15-PAL: $0-100$ scale, higher score implies better functioning. ${ }^{20}$

the majority $(70 \%)$ were outpatients, which may reflect a healthier subset of PC patients. This is further substantiated with longer survival among those receiving chemotherapy (table 2), but may also indicate that integration between oncology and PC is slowly emerging, with more emphasis on symptom control.

Cancer centres with or without inpatient PCUs recruited $>50 \%$ of the patients (table 4 ), Thus, it may be speculated that anti-cancer treatment was administered closer to the end of life in these centres than, for example, in smaller regional hospitals, as reported. ${ }^{29}$ However, the use of anti-neoplastic therapy in an acute PCU was investigated ${ }^{26}$ and it was concluded that this was limited to a small percentage of patients and was associated with characteristics such as younger age, female sex and cancer diagnoses, similar to findings in a Norwegian study. ${ }^{30}$

The ongoing discussion about chemotherapy towards the end of life is important as intensive treatment at this stage has been associated with poorer quality of life. ${ }^{6} 3132$ In this study, 15\% who died within 1 month after inclusion received chemotherapy, relative to $10 \%$ and $18 \%$ in other studies. ${ }^{30} 33$ These numbers still indicate a need for discussion and a potential for improvement. Even if conclusions about potential overtreatment cannot be drawn from this study, the percentages receiving chemotherapy seem relatively high. Although the numbers were small when split by centre categories, we found that the lowest proportion of patients getting chemotherapy during the last month was in the hospice/nursing home category (4\%), as expected, second to patients from cancer centres with PCUs (14\%; table 4). This may be because patients in the latter category were recruited from PCUs, rather than from general oncology units, implying that the principles of good PC with optimal symptom management were in the forefront, and probably that the prognostication accuracy was better. 
An important issue arising from this study relates to the representativity of the patient sample. Recruitment of centres was based on self-selection, and most institutions were hospitals and provided anti-cancer treatment as part of their PC programmes. Furthermore, $50 \%$ of centres, also including hospices, had an academic affiliation in the form of professorships and/or personnel doing research. Most centres with academic affiliations or with stakeholders involved with international networks have an obligation to do research and probably also receive some funding to do so. This is in contrast to smaller community-based centres providing PC to groups of patients with other medical and sociodemographic characteristics. On the other hand, our results point to a tendency towards more academia in PC overall and a high level of competence, although university affiliations vary throughout Europe. $^{8}$ Research is necessary to fulfil the obligation of improving the quality, competence and access to $\mathrm{PC}$, as emphasised in the EU declaration on PC. ${ }^{10}$ Thus, efforts must be taken to optimise the generalisability of research findings. Routine data collections may be useful, ${ }^{34}$ and the registration of nonparticipants in studies provides a more complete picture of PC patients. ${ }^{21} 35$ Another recommendation is related to the need for a standardised, uniform description of patient characteristics, a shortcoming that has been addressed for decades. ${ }^{36} 37$ Thus, a major strength of this study is the use of an early version of the recently published EAPC basic data set, ${ }^{11}$ consisting of a minimum set of basic sociodemographic and medical variables, supplemented by patients' self-reported symptoms.

Further, it is noteworthy that most centres had easy access to general oncology and diagnostic facilities and that $35 \%$ of patients were recruited from general oncology units, even if treatment within a PC programme was an explicit inclusion criterion. This may be taken to indicate an integration between general oncology and PC, a frequently addressed issue 38 since the Temel study in $2010,{ }^{6}$ although a global consensus on what constitutes integration is lacking. ${ }^{39}$ It should be remembered, however, that this study did not aim to explore the integration of oncology and PC per se.

It may be argued that our study is primarily a hospital-based study, as there were few other types of settings. As can be inferred from the results, there were many similarities between the hospital settings. However, since permission and access to patients for research purposes vary across and within centres, we did not specifically investigate potential differences between cancer centres and regional hospitals. To get valid results on this, a much more detailed characterisation of centres is necessary that was not feasible in a large-scale study like this.

Some limitations apply. First, comparing patient data across institutions is difficult, and it could be argued that another categorisation of centres may have given different results. On the other hand, results were relatively similar when analyses were performed with four and three categories, respectively, and significant differences were found when comparing hospices/nursing homes with the other categories. It should also be remembered that the results are based on quantitative data and do not purport to evaluate the quality of care. The relatively high percentage of potential cognitive deficits (29\%) may be attributed to the use of the 4-item MMSE version ${ }^{13}$ that lacks sufficient validation, although corresponding with other results. ${ }^{40}$ Some centres performed a consecutive sampling, whereas others recruited a convenience sample due to shortage of staff. Ideally, identical procedures should have been followed everywhere, although a complete standardisation is difficult as collaborators may have restricted access to patients. However, with more than 1600 patients, we believe that the sampling strategy did not introduce a substantial bias, compared to other studies in PC or advanced cancer, although it cannot be ruled out that the frailest patients were not included. ${ }^{21} 35$

The study's strengths are related to the participation from countries throughout Europe and beyond, representing a variety of settings that recruited more than 50 PC patients from general and specialised units, the large sample size, the use of well-known assessment tools and the simultaneous registration of patient and organisational data.

The findings from this study are helpful in informing our research agenda for future work. It is clear that heterogeneity exists, and therefore detailed characterisation in future work is imperative to facilitate comparison. We argue that there is a need to conduct prospective studies with consecutive sampling of patients who are well characterised with patientreported outcome measures and objective ratings by HCPs that seek to further define the patient population and needs in advanced cancer. This is an important step as the increasing cancer incidence and the exponential increase in the elderly means that more PC services will be outside of specialised institutions and more likely to be in non-specialist settings, particularly primary care.

\section{CONCLUSION}

The wide variation in PC services and patients across Europe is essential as it enables a true picture of PC with implications for the development of services, research and funding. It is encouraging that the advocated approach of integrated oncology and PC is being realised in many centres. The high level of research activities provides grounds for optimism that PC, traditionally regarded as a having a paucity of evidence supporting practice, is attempting to change this by integrating research. We propose that future studies provide thorough descriptions of PC 
organisation and case mix to increase the generalisability of PC research.

\section{Author affiliations}

${ }^{1}$ Department of Oncology, Regional Centre for

Excellence in Palliative Care, Oslo University

Hospital, Ullevål, Oslo, Norway

${ }^{2}$ Department of Cancer Research and Molecular

Medicine, Faculty of Medicine, European Palliative

Care Research Centre, Norwegian University of

Science and Technology (NTNU), Trondheim,

Norway

${ }^{3}$ Faculty of Medicine, University of Oslo, Oslo,

Norway

${ }^{4}$ Medical Oncology Department, University of

L'Aquila, L'Aquila, Italy

${ }^{5}$ Academic Unit of Palliative Care, Leeds Institute of

Health Sciences, University of Leeds, Leeds, UK

${ }^{6}$ Pain Therapy and Rehabilitation Unit, Department of

Palliative Care, Fondazione IRCCS Istituto Nazionale

dei Tumori, Milan, Italy

${ }^{7}$ Oncology-Hematology Department, Hospital of

Piacenza, Piacenza, Italy

${ }^{8}$ Cross Cancer Institute, Regional Cancer Centre

Northern Alberta, Edmonton, Alberta, Canada

${ }^{9}$ Instituto Português de Oncologia de Lisboa Francisco

Gentil, EPE, Lisbon, Portugal

${ }^{10}$ Regional Centre of Excellence for Palliative Care,

Western Norway, Haukeland University Hospital,

Bergen, Norway

${ }^{11}$ Department of Clinical Medicine K1, University of

Bergen, Bergen, Norway

${ }^{12}$ University of Edinburgh, Western General Hospital,

Edinburgh, UK

${ }^{13}$ Cancer Clinic, St Olavs Hospital, Trondheim

University Hospital, Trondheim, Norway

${ }^{14}$ Clínica Universidad de Navarra, Pamplona, Spain

${ }^{15}$ Hospital Universitario Arnau de Vilanova, Lleida,

Spain

${ }^{16}$ Fundación Vianorte-Laguna, Madrid, Spain

${ }^{17}$ End-of-Life Care Research Group, Ghent University

\& Vrije Universiteit Brussel (VUB), Brussels, Belgium

${ }^{18}$ Department of Medical Oncology, Ghent University

Hospital, Ghent, Belgium

${ }^{19}$ Unità di Cure Palliative Azienda Ospedaliera San

Paolo, Milan, Italy

${ }^{20}$ Palliative Care Service, Catalan Institute of

Oncology (ICO), Barcelona, Spain

${ }^{21}$ Bellvitge Biomedical Research Institute (IDIBELL),

WeCare Chair: end of life care, Barcelona, Spain

${ }^{22}$ Universitat Internacional de Catalunya, Barcelona,

Spain

${ }^{23}$ U.O. Complessa Cure Palliative e Terapia del Dolore

Istituti Clinici di Perfezionamento, Milan, Italy

${ }^{24}$ Arcispedale Santa Maria Nuova-IRCCS, Reggio

Emilia, Italy

${ }^{25}$ Section of Palliative Medicine, Department of

Oncology, Rigshospitalet, Copenhagen, Denmark
${ }^{26}$ Oncological Palliative Medicine, Oncology

Department, Internal Medicine \& Palliative Centre

Cantonal Hospital, St. Gallen, Switzerland

${ }^{27}$ Hospice Villa Speranza, Università Cattolica

S. Cuore, Rome, Italy

Correction notice This article has been corrected since it published Online First. An Open Access licence has been added.

Acknowledgements The authors want to express their gratitude to Professor Jon H. Loge, Oslo University Hospital, for valuable advice during the preparation of this manuscript and Hanne C. Lie, PhD, University of Oslo, for statistical advice.

Collaborators The European Palliative Care Cancer Symptom study (EPCCS) is a collaborative effort between the European Palliative Care Research Centre (PRC) and the European Association for Palliative Care-Research Network (EAPC-RN). EPCCS was partially funded by grant no. 6070 from the Research Council at Norwegian University of Science and Technology (NTNU) and St. Olavs Hospital-Trondheim University Hospital, grant no. 46055100 from the Regional Health Authorities, Central Norway, and by an unrestricted grant from the Helsinn group, Switzerland. C Brunelli has received a training grant from the Floriani Foundation-Milan (del. CDA 22/11/12). Project management: Marianne J. Hjermstad, PRC/NTNU; Stein Kaasa, PRC/NTNU/ EAPC-RN; Dagny F. Haugen, PRC/NTNU; Pål Klepstad PRC/ NTNU and Gunnhild Jakobsen PRC/NTNU, Norway; Augusto Caraceni, PRC/EAPC-RN and Cinzia Brunelli, PRC/Italy; Per Sjøgren, EAPC-RN, Denmark; Florian Strasser, Switzerland; Barry Laird, PRC/UK. Project steering committee: Marianne J. Hjermstad, PRC/NTNU and Stein Kaasa, PRC/NTNU/ EAPC-RN, Norway; Augusto Caraceni, PRC/EAPC-RN and Cinzia Brunelli, PRC/Italy; Per Sjøgren, EAPC-RN, Denmark, Luc Deliens, EAPC-RN, Belgium, Mike Bennett, EAPC-RN, UK; David Currow, Australia; Vickie Baracos, Canada. Core centre collaborators, one from each site: Erik Løhre, St. Olavs Hospital-Trondheim University Hospital; Nina Aass, Oslo University Hospital; Elisabeth Brenne, Øya Helsehus and Inge Raknes, Haraldsplass Deaconess Hospital, Norway; Geana Kurita, Rigshospitalet and Mogens Groenvold, Bispebjerg Hospital, Denmark; Florian Strasser, Cantonal Hospital St. Gallen and Cristian Camartin, Kantonspital, Graubünden, Switzerland; Alessandra Pigni, Fondazione IRCCS Istituto Nazionale dei Tumori, Luigi Cavanna, Oncologia Medica Ospedale Di PiacenzA; Adriana Turriziani, Hospice Villa Speranza Roma; Franco Rizzi, U.O. Complessa di Cure Palliative e Terapia del Dolore. AO ICP Milan; Laura Piva; Unità di Cure Palliative Azienda Ospedaliera San Paolo, Milan; Giampiero Porzio, Oncologia Medica Università degli Studi, L'Aquila and Rondini Ermanno, U.O. Oncologia Medica Arcispedale S. Maria Nuova-IRCCS, Reggio Emilia, Italy; Mike Bennett, Leeds Institute of Health Sciences/University of Leeds; Barry Laird, Western General Hospital Edinburgh/ Beatson West of Scotland Cancer Centre, Edinburgh; Andrew Wilcock, Nottingham University Hospitals NHS Trust,

Nottingham and Karen Harvie, Marie Curie Hospice, Glasgow, UK; Maria Nabal, Hospital Universitário Arnau de Vilanova Lleida, Antonio N. Tejedor, Hospital Centro de Cuidados Laguna, Madrid; Josep Porta Sales, Institut Català d'Oncologia, Barcelona and Marina Martínez, Clinica Universidad De Navarra Pamplona, Spain; Konrad Fassbender, University of Alberta, Canada, David Currow, Flinders University, Australia; Nikolay Yordanov, Comprehensive Cancer Centre Vratsa, Bulgaria; Koen Pardon, Ghent University Hospital Flanders, Belgium; Ioseb Abesadze, Cancer Prevention Centre, Tblisi, Georgia, Madalena Feio, Instituto Português de Oncologia Francisco Gentil Lisbon, Portugal.

Contributors All authors have recruited 50 patients or more to the study, registered data, stored these and been responsible for shipment of forms to the trial office. All authors have commented on the manuscript drafts, the final version and approved the submitted manuscript. All authors outside 
Norway have assisted in the preparation of study forms and documents and been responsible for ethics approvals and study conduct at their sites. MJH, PS, BL, CB, SK, GJ and AC are responsible for the study initiation and protocol. SK and $\mathrm{MJH}$ have applied for and received funding.

Funding Central Norway Regional Health Authority (grant no. 46055100), The Cancer Foundation St Olavs Hospital, Trondheim University Hospital (grant no. 6070) and an unrestricted grant from the Helsinn group, Switzerland.

Competing interests None declared.

Ethics approval Norway: REC East Norway + all ethical committees at each study site and country site.

Provenance and peer review Not commissioned; externally peer reviewed.

Data sharing statement Since this is a non-profit study with limited funding and no financial incentives to study collaborators (or patients), the database will be shared with the study responsible at each study site. Several manuscripts are forthcoming that represent no replications of the data presented in the manuscript submitted here to BMJ SupporPall Care, as this is the main publication from the EPCCS study. Therefore, other EPCCS publications were intended for publication after acceptance of this submitted publication. One paper was published as E-pub ahead of print, April 2016

(PMID:27061408). Further, all publications are subject to approval by the project management group to avoid conflicts and dual publications. As of now, data are shared with: Australia, D Currow: breathlessness, Belgium; K Pardon/L Deliens, depression + local integration, Norway: JH Loge/ Hjermstad: pain and depression, Norway: Skeidsvoll: cachexia, Norway: Klepstad: Breakthrough pain, Spain: Noguera/ Centeno: Hospital vs home care, Denmark: Sjøgren/Kurita: Cognitive function, Switzerland: Strasser/Hui: Integration.

Open Access This is an Open Access article distributed in accordance with the Creative Commons Attribution Non Commercial (CC BY-NC 4.0) license, which permits others to distribute, remix, adapt, build upon this work noncommercially, and license their derivative works on different terms, provided the original work is properly cited and the use is non-commercial. See: http://creativecommons.org/licenses/by$\mathrm{nc} / 4.0 /$

\section{REFERENCES}

1 World Health Organization. 2011. http://www.who.int/cancer/ palliative/definition/en (accessed 26 Jul 2015).

2 World Health Organization. Worldwide Palliative Care Alliance. Global atlas of palliative care at the end of life. 2014. http:// www.who.int/mediacentre/news/releases/2014/ palliative-care-20140128/en/ (accessed 26 Jul 2015).

3 Smith TJ, Temin S, Alesi ER, et al. American Society of Clinical Oncology provisional clinical opinion: the integration of palliative care into standard oncology care. J Clin Oncol 2012;30:880-7.

4 Hui D, Kim SH, Kwon JH, et al. Access to palliative care among patients treated at a comprehensive cancer center. Oncologist 2012;17:1574-80.

5 Bakitas MA, Tosteson TD, Li Z, et al. Early versus delayed initiation of concurrent palliative oncology care: patient outcomes in the ENABLE III randomized controlled trial. $J$ Clin Oncol 2015;33:1438-45.

6 Temel JS, Greer JA, Muzikansky A, et al. Early palliative care for patients with metastatic non-small-cell lung cancer. N Engl J Med 2010;363:733-42.

7 Yennurajalingam S, Kang JH, Hui D, et al. Clinical response to an outpatient palliative care consultation in patients with advanced cancer and cancer pain. J Pain Symptom Manage 2012;44:340-50.
8 European Association for Palliative Care. EAPC Atlas of Palliative Care in Europe 2013, Cartographic Edition. 2014. http://www.unav.es/centro/cultura-y-sociedad/ (accessed 23 Jul 2015).

9 Kaasa S, Hjermstad MJ, Loge JH. Methodological and structural challenges in palliative care research: how have we fared in the last decades? Palliat Med 2006;20:727-34.

10 The 2014 European Declaration on Palliative Care: towards integration of palliative care in an age-friendly EU. 2014. http://www.palliativecare2020.eu/declaration/ (accessed $26 \mathrm{Jul}$ 2015).

11 Sigurdardottir KR, Kaasa S, Rosland JH, et al. The European Association for Palliative Care basic dataset to describe a palliative care cancer population: results from an international Delphi process. Palliat Med 2014;28:463-73.

12 Folstein MF, Folstein SE, McHugh PR. Mini-mental state: a practical method for grading the cognitive state of patients for the clinician. J Psychiatr Res 1975;12:189-98.

13 Fayers PM, Hjermstad MJ, Ranhoff AH, et al. Which mini-mental state exam items can be used to screen for delirium and cognitive impairment? J Pain Symptom Manage 2005;30:41-50.

14 Karnofsky D, Burchenal J. The clinical evaluation of chemotherapeutic agents in cancer. In: Macleod C, ed. Evaluation of chemotherapeutic agents. New York: Columbia University Press, 1949:199-205.

15 Daut RL, Cleeland CS, Flanery RC. Development of the Wisconsin Brief Pain Questionnaire to assess pain in cancer and other diseases. Pain 1983;17:197-210.

16 Freynhagen R, Baron R, Gockel U, et al. painDETECT: a new screening questionnaire to identify neuropathic components in patients with back pain. Curr Med Res Opin 2006;22:1911-20,

17 Hagen NA, Stiles C, Nekolaichuk C, et al. The Alberta Breakthrough Pain Assessment Tool for cancer patients: a validation study using a delphi process and patient think-aloud interviews. J Pain Symptom Manage 2008;35:136-52.

18 Spitzer RL, Kroenke K, Williams JB. Validation and utility of a self-report version of PRIME-MD: the PHQ primary care study. JAMA 1999;282:1737-44.

19 Watanabe SM, Nekolaichuk C, Beaumont C, et al. A multi-center study comparing two numerical versions of the Edmonton Symptom Assessment System in palliative care patients. J Pain Symptom Manage 2011;41:456-68.

20 Groenvold M, Petersen MA, Aaronson NK, et al. The development of the EORTC QLQ-C15-PAL: a shortened questionnaire for cancer patients in palliative care. Eur J Cancer 2006;42:55-64.

21 Hjermstad MJ, Lie HC, Caraceni A, et al. Computer-based symptom assessment is feasible in patients with advanced cancer: results from an international multicenter study, the EPCRC-CSA. J Pain Symptom Manage 2012;44:639-54.

22 Laugsand EA, Kaasa S, de Conno F, et al. Intensity and treatment of symptoms in 3,030 palliative care patients: a cross-sectional survey of the EAPC Research Network. J Opioid Manag 2009;1:11-21.

23 Zimmermann C, Swami N, Krzyzanowska M, et al. Early palliative care for patients with advanced cancer: a cluster-randomised controlled trial. Lancet 2014;383: 1721-30.

24 Modonesi C, Scarpi E, Maltoni M, et al. Impact of palliative care unit admission on symptom control evaluated by the Edmonton Symptom Assessment System. J Pain Symptom Manage 2005;30:367-73. 
25 Dalal S, Palla S, Hui D, et al. Association between a name change from palliative to supportive care and the timing of patient referrals at a comprehensive cancer center. Oncologist 2011;16:105-11.

26 Hui D, Elsayem A, Li Z, et al. Antineoplastic therapy use in patients with advanced cancer admitted to an acute palliative care unit at a comprehensive cancer center: a simultaneous care model. Cancer 2010;116 (2036-43.

27 Greco MT, Roberto A, Corli O, et al. Quality of cancer pain management: an update of a systematic review of undertreatment of patients with cancer. J Clin Oncol 2014;32:4149-54.

28 Deandrea S, Corli O, Consonni D, et al. Prevalence of breakthrough cancer pain: a systematic review and a pooled analysis of published literature. J Pain Symptom Manage 2014;47:57-76.

29 Earle CC, Landrum MB, Souza JM, et al. Aggressiveness of cancer care near the end of life: is it a quality-of-care issue? J Clin Oncol 2008;26:3860-6.

30 Anshushaug M, Gynnild MA, Kaasa S, et al. Characterization of patients receiving palliative chemo- and radiotherapy during end of life at a regional cancer center in Norway. Acta Oncol 2015;54:395-402.

31 Greer JA, Pirl WF, Jackson VA, et al. Effect of early palliative care on chemotherapy use and end-of-life care in patients with metastatic non-small-cell lung cancer. J Clin Oncol 2012;30:394-400.

32 Wright AA, Zhang B, Ray A, et al. Associations between endof-life discussions, patient mental health, medical care near death, and caregiver bereavement adjustment. JAMA 2008;300:1665-73.

33 Kao S, Shafiq J, Vardy J, et al. Use of chemotherapy at end of life in oncology patients. Ann Oncol 2009;20:1555-9.

34 Currow DC, Allingham S, Yates P, et al. Improving national hospice/palliative care service symptom outcomes systematically through point-of-care data collection, structured feedback and benchmarking. Support Care Cancer 2015;23:307-15.

35 Stone PC, Gwilliam B, Keeley V, et al. Factors affecting recruitment to an observational multicentre palliative care study. BMJ Support Palliat Care 2013;3: 318-23.

36 Borgsteede SD, Deliens L, Francke AL, et al. Defining the patient population: one of the problems for palliative care research. Palliat Med 2006;20:63-8.

37 Currow DC, Wheeler JL, Glare PA, et al. A framework for generalizability in palliative care. J Pain Symptom Manage 2009;37:373-86.

38 Gomes B. Palliative care: if it makes a difference, why wait? J Clin Oncol 2015;33:1420-1.

39 Hui D, Kim YJ, Park JC, et al. Integration of oncology and palliative care: a systematic review. Oncologist 2015;20:77-83.

40 Kurita GP, Sjøgren P, Ekholm O, et al. Prevalence and predictors of cognitive dysfunction in opioid-treated patients with cancer: a multinational study. J Clin Oncol 2011;29:1297-303. 